\title{
Differential Effects of Direct and Indirect Dopamine Agonists on Prepulse Inhibition: A Study in D1 and D2 Receptor Knock-Out Mice
}

\author{
Rebecca J. Ralph-Williams, ${ }^{1}$ Virginia Lehmann-Masten, ${ }^{2}$ Veronica Otero-Corchon,, ${ }^{3}$ Malcolm J. Low, ${ }^{3,4}$ and \\ Mark A. Geyer ${ }^{2}$ \\ ${ }_{1}^{1}$ Alcohol and Drug Abuse Research Center, Harvard Medical School and McLean Hospital, Belmont, Massachusetts \\ 02478, 2Department of Psychiatry, University of California, San Diego, La Jolla, California 92093-0804, 3Vollum Institute \\ and ${ }^{4}$ Department of Behavioral Neuroscience, Oregon Health and Science University, Portland, Oregon 97201
}

\begin{abstract}
Stimulation of the dopamine (DA) system disrupts prepulse inhibition (PPI) of the acoustic startle response. On the basis of rat studies, it appeared that DA D2 receptors (D2Rs) rather than D1 receptors (D1Rs) regulate $\mathrm{PPI}$, albeit possibly in synergism with D1Rs. To characterize the DA receptor modulation of PPI in another species, we tested DA D1R and D2R mutant mice with direct and indirect DA agonists and with the glutamate receptor antagonist, dizocilpine (MK-801). Neither the mixed D1/D2 agonist apomorphine $(5 \mathrm{mg} / \mathrm{kg})$ nor the more selective D1-like agonist SKF82958 (0.3 mg/kg) altered PPI in D1R knock-out mice, although both compounds disrupted PPI in D2R mutant and wild-type mice, suggesting that the D1R alone might modulate PPI in mice. However, amphetamine $(10 \mathrm{mg} / \mathrm{kg})$ significantly lowered PPI in each genotype of D1R mice, suggesting that the D1R is not necessary for the PPI-disruptive effect of the
\end{abstract}

indirect agonist in mice. As reported previously, amphetamine (10 mg/kg) failed to disrupt PPI in D2R knock-out mice, supporting a unique role of the D2R in the modulation of PPI. Dizocilpine $(0.3 \mathrm{mg} / \mathrm{kg})$ induced similar PPI deficits in D1R and D2R mutant mice, confirming that the influences of the NMDA receptor on PPI are independent of D1Rs and D2Rs in rodents. Thus, both D1Rs and D2Rs modulate aspects of PPI in mice in a manner that differs from dopaminergic modulation in rats. These findings emphasize that further cross-species comparisons of the pharmacology of PPI are essential to understand the relevance of rodent PPI studies to the deficits in PPI observed in patients with schizophrenia.

Key words: prepulse inhibition; mice; dopamine; D1 receptor; D2 receptor; knock-out; apomorphine; SKF82958; amphetamine; dizocilpine; startle response
Filtering or "gating" mechanisms are essential for normal attention and cognition. In some psychiatric disorders, such as schizophrenia, deficient gating mechanisms are thought to lead to sensory overload and subsequent cognitive fragmentation (McGhie and Chapman, 1961; Braff and Geyer, 1990; Braff et al., 1992). One operational measure of sensorimotor gating mechanisms is prepulse inhibition (PPI) of the startle response. PPI occurs when a low-intensity prepulse precedes a startle stimulus, resulting in a reduced startle response (Hoffman and Ison, 1980). In studies using rodents, both typical and atypical antipsychotics reversed apomorphine-induced disruptions of PPI (Geyer et al., 2001); their ability to reverse these deficits correlates with both their clinical efficacy and their affinity for the dopamine (DA) D2 receptor (Swerdlow et al., 1994). By understanding the neural substrates that regulate PPI in rodents, key elements of the pathophysiology of neuropsychiatric disorders characterized by sensorimotor gating deficits may be elucidated.

A rich literature describes the effects of pharmacological manipulations of the DA system on measures of PPI in rats. Inves-

\footnotetext{
Received June 14, 2002; revised Aug. 1, 2002; accepted Aug. 16, 2002.

This work was supported by Grants MH61326 and F31-MH12806 from the National Institute of Mental Health and by the U.S. Veterans Administration VISN 22 Mental Illness Research Education and Clinical Center. M.A.G. holds an equity interest in San Diego Instruments, Inc. We thank David Gallagher and Mahálah Buell for excellent technical assistance.

Correspondence should be addressed to Dr. Mark A. Geyer, Department of Psychiatry, University of California, San Diego, 9500 Gilman Drive, La Jolla, CA 92093-0804. E-mail: mgeyer@ucsd.edu.

Copyright () 2002 Society for Neuroscience $0270-6474 / 02 / 229604-\bullet \$ 15.00 / 0$
}

tigations into which of the specific DA receptor subtypes modulate PPI in rats have revealed a major contribution of the D2 receptor (D2R) family and a lesser contribution of the D1 receptor (D1R) family (for review, see Geyer et al., 2001). Indeed, the vast majority of evidence indicates that D2Rs rather than D1Rs regulate PPI in rats, possibly in synergism with D1Rs. More recently, the DA pharmacology of PPI has been investigated in mouse models. Similar to reports in rats, it appears that both D1Rs and D2Rs are involved in the modulation of PPI in mice. Both amphetamine and apomorphine disrupt PPI in mice, and an apomorphine-induced decrease in PPI is reversed by the D2-like antagonist haloperidol (Curzon and Decker, 1998; Furuya et al., 1999; Geyer et al., 2002). We have reported previously that amphetamine does not disrupt PPI in mice that lack the D2R but have fully functional D1Rs, providing more evidence that the D2R contributes to the dopaminergic modulation of PPI in mice (Ralph et al., 1999). Furthermore, the disruptions in PPI found in DA transporter (DAT) $(-/-)$ mice are reversed by D2-like, but not D1-like, antagonists, suggesting that the D2R is a key modulator of PPI in mice (Ralph et al., 2001a). However, of note are recent findings that the D2-like agonist quinpirole failed to disrupt PPI, whereas the D1-like agonists SKF82958, SKF81297, and dihydrexidine significantly reduced PPI in mice, suggesting that the D1R might have a more prominent role in the regulation of PPI in mice than in rats (Holmes et al., 2001; Ralph-Williams et al., 2002).

Describing specific DA receptor regulation of PPI using only pharmacological manipulations is complicated by the lack of 
specific ligands for each DA receptor subtype. Hence, to further examine the DA receptor modulation of PPI in mice, we tested PPI in D1 and D2 receptor mutant mice treated with the mixed D1/D2 agonist apomorphine, the D1-like agonist SKF82958, the indirect DA agonist amphetamine, and the NMDA antagonist dizocilpine.

\section{MATERIALS AND METHODS}

Animals. A colony of D1R mutant mice (Drago et al., 1994) was established at Oregon Health and Science University from breeding stock of B6.129S4-Drd1 ${ }^{\text {tm IJcd }}$ male mice obtained from The Jackson Laboratory (Bar Harbor, ME). The heterozygous $(+/-)$ mice had been backcrossed for a minimum of five generations onto the inbred C57BL/6J line before importation and were then backcrossed for two additional generations at the Vollum Institute to produce incipient congenic (N7) mice. N7 C57BL/6J heterozygous $(+/-)$ breeding pairs were used to generate the mice for behavioral studies. Because the homozygous $(-/-)$ mice are growth-retarded (Drago et al., 1994), pups were not weaned from their mothers until 4 weeks of age and were then provided with moistened chow until $\sim 8$ weeks of age to maximize growth. All mice were genotyped by PCR analysis of genomic DNA using a multiplex protocol provided by The Jackson Laboratory. The wild-type Drd1 allele was amplified to a $350 \mathrm{bp}$ product using the forward primer 5'-AAAGTTCCTTTAAGATGTCCT- $3^{\prime}$ and the reverse primer $5^{\prime}$-TGGTGGCTGGAAAACATCAGA- $3^{\prime}$. The targeted $\operatorname{Drd} 1$ allele was amplified to a $280 \mathrm{bp}$ product using the Neo1 generic neo primer 5'-CTTGGGTGGAGAGGCTATTC-3' and the Neo2 generic neo primer 5'-AGGTGAGATGACAGGAGATC-3'. Two separate cohorts of D1R mice were used in the experiments described herein. The first D1R cohort (tested with apomorphine and dizocilpine) consisted of 50 wild-type $(+/+)$ ( 22 females, 28 males), 63 heterozygous $(+/-)$ (31 females, 32 males), and 31 knock-out $(-/-)$ (14 females, 17 males) mice. A second D1R cohort (tested with SKF82958 and amphetamine) consisted of 60 wild-type $(+/+)$ (31 females, 29 males), 19 heterozygous $(+/-)$ ( 9 females, 10 males $)$, and 40 knock-out $(-/-)(26$ females, 14 males) mice. D1R heterozygous $(+/-)$ mice were not included in the SKF82958 study because they were needed to establish a new D1R breeding colony. The D2R mutant mice (Kelly et al., 1997, 1998), official strain designation B6.129S2-Drd2 ${ }^{\text {tmllow }}$, were originally generated at Oregon Health and Science University and backcrossed for eight generations (N8) onto the inbred C57BL/6J line (The Jackson Laboratory). Heterozygous $(+/-)$ breeding pairs of N8 incipient congenic D2R mice were used to establish a colony of the mice at the University of California, San Diego; two separate cohorts of mice were genotyped by PCR as described previously (Diaz-Torga et al., 2002). The first D2R cohort of mice (tested with apomorphine and SKF82958) consisted of 16 wild-type $(+/+)$ (4 females, 12 males), 23 heterozygous $(+/-)$ ( 7 females, 16 males), and 14 knock-out $(-/-)$ (8 females, 6 males) mice; the second cohort (tested with dizocilpine and amphetamine) consisted of 8 wild-type $(+/+)$ ( 7 females, 1 male), 16 heterozygous $(+/-)$ ( 9 females, 7 males), and 11 knock-out $(-/-)$ (4 females, 7 males) mice. All behavioral testing procedures were approved by an institutional animal care and use committee before the onset of the experiments. Mice were maintained in animal facilities approved by the American Association for Accreditation of Laboratory Animal Care at the San Diego Veterans Administration Hospital (La Jolla, CA) or the University of California, San Diego. These facilities meet all federal and state requirements for animal care. At weaning, mice from each experiment were separated by sex and group-housed (with littermates whenever possible) in a climate-controlled animal colony with a reversed light/dark cycle (lights on at 7:00 P.M., off at 7:00 A.M.).

All behavioral testing started at $\sim 14$ weeks of age and occurred between 9:00 A.M. and 5:00 P.M. Food (Harlan Teklab, Madison, WI) and water were available ad libitum, except during behavioral testing.

Drug experiments. All drugs used in these experiments were obtained from Sigma (St. Louis, MO). Apomorphine was dissolved in $0.1 \%$ ascorbic acid, and SKF82958, dizocilpine (also known as MK-801), and $d$-amphetamine were dissolved in sterile water. Apomorphine was given subcutaneously, whereas SKF82958, dizocilpine, and amphetamine were given intraperitoneally. Doses for each drug were chosen on the basis of previous reports in the literature using mice [apomorphine, $5.0 \mathrm{mg} / \mathrm{kg}$ (Dulawa and Geyer, 1996); SKF82958, $0.3 \mathrm{mg} / \mathrm{kg}$ (Ralph-Williams et al., 2002); dizocilpine, $0.3 \mathrm{mg} / \mathrm{kg}$ (Curzon and Decker, 1998); amphetamine, $10.0 \mathrm{mg} / \mathrm{kg}$ (Ralph et al., 1999, 2001b)]. Injections were given at a volume of $5 \mathrm{ml} / \mathrm{kg}$ body weight.
Apparatus. Startle reactivity was measured using four startle chambers (SR-LAB, San Diego Instruments, San Diego, CA). Each chamber consisted of a clear nonrestrictive Plexiglas cylinder resting on a platform inside a ventilated box. A high-frequency loudspeaker inside the chamber produced both a continuous background noise of $65 \mathrm{~dB}$ and the various acoustic stimuli. Vibrations of the Plexiglas cylinder caused by the wholebody startle response of the animal were transduced into analog signals by a piezoelectric unit attached to the platform. These signals were then digitized and stored by a computer. Sixty-five readings were taken at 1 msec intervals, starting at stimulus onset, and the average amplitude was used to determine the acoustic startle response. Sound levels in decibels sound pressure level (A scale) were measured as described previously (Dulawa et al., 1997). The SR-LAB calibration unit was used routinely to ensure consistent stabilimeter sensitivity between test chambers and over time (Geyer and Swerdlow, 1998).

Prepulse inhibition session. All PPI test sessions consisted of startle trials (pulse-alone), prepulse trials (prepulse + pulse), and no-stimulus trials (nostim). The pulse-alone trial consisted of a $40 \mathrm{msec} 120 \mathrm{~dB}$ pulse of broad-band noise. PPI was measured by prepulse + pulse trials that consisted of a $20 \mathrm{msec}$ noise prepulse, $100 \mathrm{msec}$ delay, then a $40 \mathrm{msec} 120$ $\mathrm{dB}$ startle pulse (120 msec onset-to-onset interval). The acoustic prepulse intensities were 4, 8 , and $16 \mathrm{~dB}$ above the $65 \mathrm{~dB}$ background noise (i.e., 69,73 , and $81 \mathrm{~dB}$ ). The nostim trial consisted of background noise only. The test session began and ended with five presentations of the pulseALONE trial; in between, each acoustic or nostim trial type was presented 10 times in a pseudorandom order. There was an average of $15 \mathrm{sec}$ (range, 12-30 sec) between trials. The mice were placed into the startle chambers immediately after each injection, and a $65 \mathrm{~dB}$ background noise level was presented for a 10 min acclimation period and continued throughout the test session.

In each experiment, mice were assigned to receive either drug or vehicle (balanced for genotype, sex, startle chamber assignment, and treatment) and were tested in the PPI session. In experiments using D1R mice, a between-subjects design was used because of the large number of mice available; however, because of limited availability, the D2R mice were tested again 1 week after their first test, counterbalanced for drug treatment, to complete a within-subjects design. The order of drug treatment for the first D1R cohort was apomorphine, followed by dizocilpine; the second D1R cohort received SKF82958 and then amphetamine. The order of drug treatment for the D2R cohort was apomorphine followed by SKF82958; the second D2R cohort received dizocilpine and then amphetamine. All drug experiments were separated by at least 1 week.

The amount of PPI was calculated as a percentage score for each acoustic prepulse trial type: $\%$ PPI $=100-\{[$ (startle response for prepulse + pulse $) /($ startle response for pulse-alone $)] \times 100\}$. The magnitude of the acoustic startle response was calculated as the average response to all of the pulse-alone trials, excluding the first and last blocks of five pulse-alone trials presented. For brevity, the main effects of prepulse intensity (which were always significant) will not be discussed. Data from the nostim trials are not included in Results because the values were negligible relative to values from trials containing startle stimuli.

Statistical analyses. In the D1R statistical analyses, the genotype and drug treatment were between-subjects variables, and the prepulse intensity was a within-subjects variable. In the D2R statistical analyses, the genotype was a between-subjects variable, and drug treatment and prepulse intensity were within-subjects variables. ANOVAs were used to compare means, and the $\alpha$ level was adjusted to $p<0.025$ to accommodate the removal of genotype as a factor in the D2R post hoc ANOVAs. Because there were no significant interactions between sex and either gene or drug in the D1R or D2R cohorts of mice, data from female and male mice were combined. The computations were performed using BMDP statistical software (Statistical Solutions, Saugus, MA).

\section{RESULTS}

\section{Apomorphine}

D1R mutant mice were given the DA D1/D2 agonist apomorphine, a compound known to disrupt PPI in both rats and mice (Geyer et al., 2001, 2002). There was a significant main effect of drug treatment $\left(F_{(1,138)}=34.7 ; p<0.001\right)$, a main effect of genotype $\left(F_{(2,138)}=5.5 ; p<0.01\right)$, and, more importantly, a significant interaction between drug and genotype $\left(F_{(2,138)}=6.8\right.$; $p<0.01)$. Apomorphine significantly lowered PPI in both the 

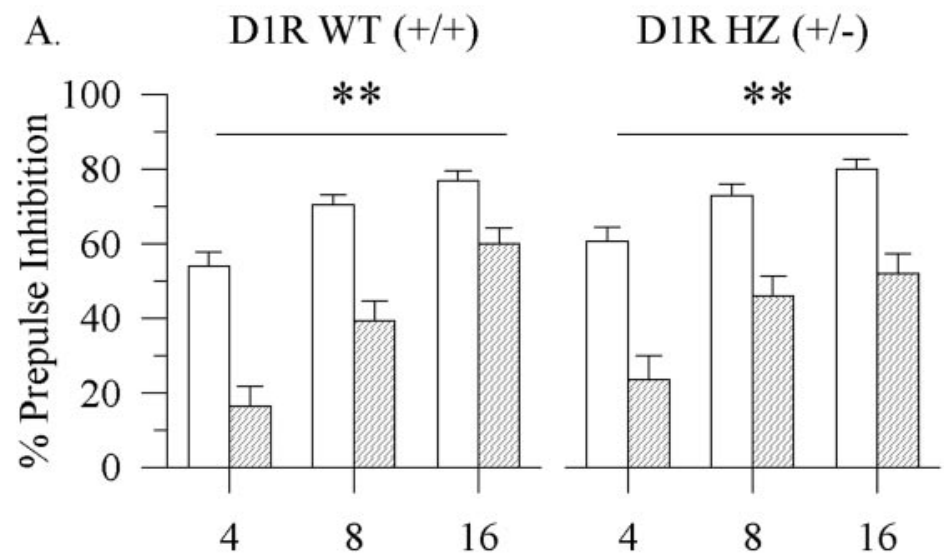

D1R KO (-/-)

B.

D2R WT $(+/+)$

D2R HZ (+/-)
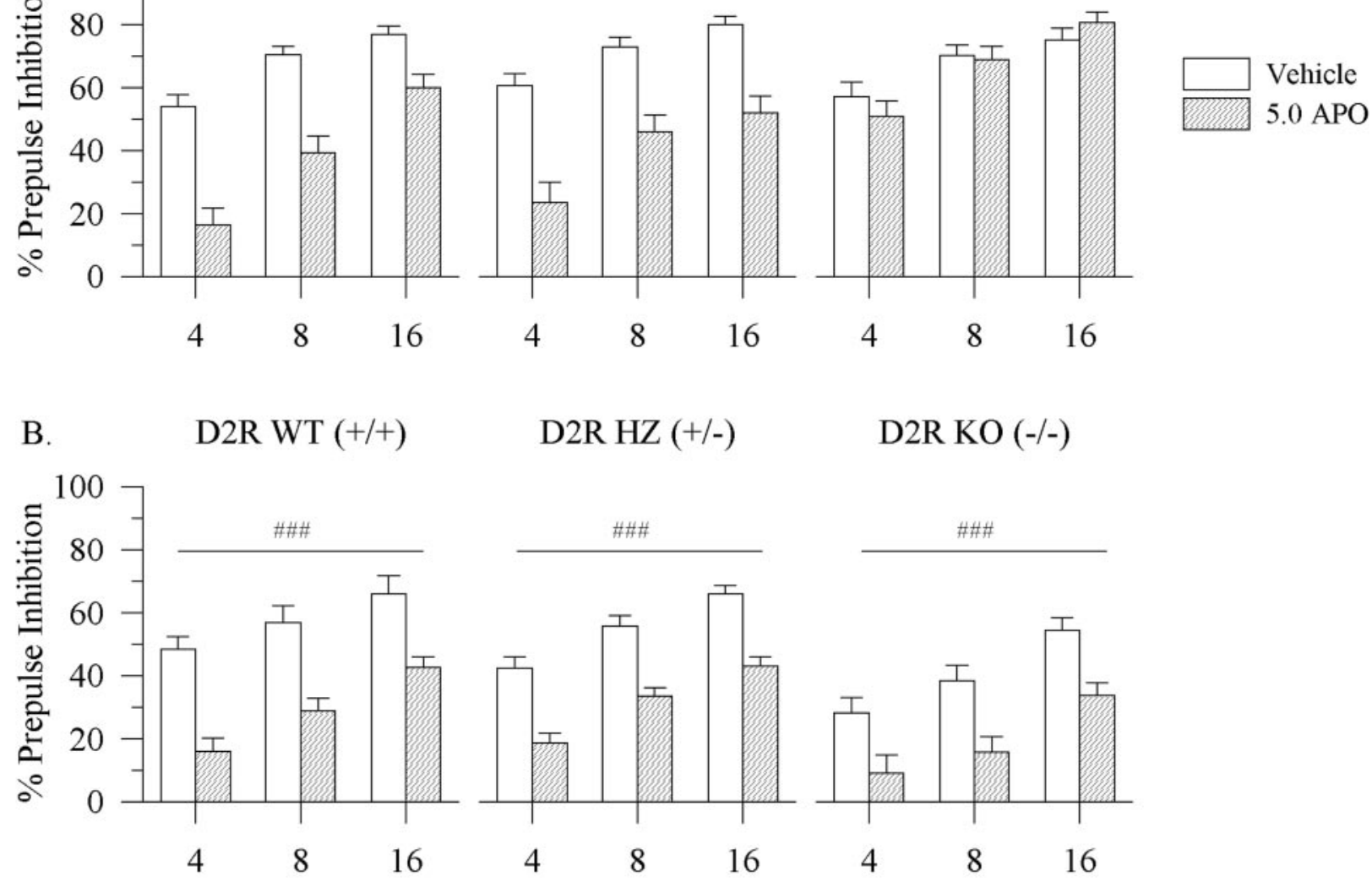

Prepulse Intensity $(\mathrm{dB})$

Figure 1. PPI levels in D1R and D2R mice after pretreatment with vehicle ( $0.1 \%$ ascorbic acid; open bars) or apomorphine (APO) (5.0 mg/kg; hatched bars). $A$, The mixed D1/D2 agonist apomorphine decreased PPI in both the D1R wild-type $(W T,+/+)$ and heterozygous $(H Z,+/-)$ mice but was ineffective in the D1R knock-out $(K O,-/-)$ mice. ${ }^{* *} p<0.01$ compared with vehicle control. $B$, Apomorphine disrupted PPI in all D2R mutant mice, regardless of genotype (overall drug effect, ${ }^{\# \# \#} p<0.001$ ). Error bars indicate mean \% PPI \pm SEM.

wild-type $(+/+)$ and heterozygous $(+/-)$ mice at each prepulse intensity $(p<0.01)$ (Fig. $1 A)$, but these PPI-disruptive effects were absent in mice that lacked the D1R (Fig. 1A). However, apomorphine did exert some behavioral effects in the D1R knockout $(-/-)$ mice. There was a main effect of apomorphine on startle reactivity $\left(F_{(1,138)}=25.7 ; p<0.01\right)$, but there were no effects of genotype or interactions. Apomorphine reduced startle reactivity in all three $\mathrm{D} 1 \mathrm{R}$ genotypes (Table 1$)$.

When the D2R mutant mice were challenged with apomorphine, there was a significant main effect of drug treatment on PPI $\left(F_{(1,50)}=56.6 ; p<0.001\right)$. There was also a significant main effect of genotype $\left(F_{(2,50)}=5.9 ; p<0.01\right)$, but there were no interactions between genotype and drug treatment. The D2R knock-out $(-/-)$ mice had lower PPIs compared with the wild-type $(+/+)$ controls, but apomorphine significantly disrupted PPI in all of the D2R genotypes (Fig. $1 B$ ). As with the D1R mice, there was also a main effect of drug treatment on startle reactivity $\left(F_{(1,50)}=\right.$ 40.4; $p<0.001)$; apomorphine reduced startle responding in the D2R wild-type $(+/+)$, heterozygous $(+/-)$, and knock-out $(-/-)$ mice (Table 2).

\section{SKF82958}

It has been postulated that the D1R and D2R subtypes interact synergistically to modulate PPI in the rat (Peng et al., 1990;
Table 1. Acoustic startle reactivity in D1R wild-type $(+/+)$, heterozygous (+/-), and knock-out (-/-) mice

\begin{tabular}{lccc} 
& D1R $(+/+)$ & D1R $(+/-)$ & D1R $(-/-)$ \\
\hline Apomorphine (ME) & & & \\
$\quad$ Vehicle & $84.4 \pm 11.3$ & $73.2 \pm 8.0$ & $97.4 \pm 9.9$ \\
$5.0 \mathrm{mg} / \mathrm{kg}$ & $50.6 \pm 5.8^{*}$ & $41.9 \pm 5.9^{*}$ & $48.5 \pm 11.9^{*}$ \\
SKF82958 & & & \\
$\quad$ Vehicle & $115.0 \pm 21.3$ & not tested & $84.0 \pm 14.5$ \\
$\quad 0.30 \mathrm{mg} / \mathrm{kg}$ & $60.3 \pm 6.4$ & not tested & $106.9 \pm 17.7$ \\
Amphetamine (ME) & & & \\
$\quad$ Vehicle & $128.0 \pm 14.6$ & $94.1 \pm 16.5$ & $112.0 \pm 10.2$ \\
$10.0 \mathrm{mg} / \mathrm{kg}$ & $80.7 \pm 9.7^{*}$ & $50.3 \pm 14.8^{*}$ & $59.3 \pm 8.3^{*}$ \\
Dizocilpine & & & \\
$\quad$ Vehicle & $69.7 \pm 9.1$ & $57.2 \pm 6.0$ & $76.7 \pm 14.9$ \\
$0.3 \mathrm{mg} / \mathrm{kg}$ & $91.3 \pm 7.6$ & $81.8 \pm 9.3$ & $59.5 \pm 8.0$
\end{tabular}

Values (arbitrary units) represent mean startle magnitude \pm SEM.

${ }^{*} p<0.05$ compared with vehicle control or main effect of drug treatment (ME).

Schwarzkopf et al., 1993; Wan et al., 1996). To investigate the interaction of D1Rs and D2Rs in mice, we challenged both the D1R and D2R mutant mice with the preferential D1-like agonist, 


\begin{tabular}{|c|c|c|c|}
\hline & $\mathrm{D} 2 \mathrm{R}(+/+)$ & $\mathrm{D} 2 \mathrm{R}(+/-)$ & $\mathrm{D} 2 \mathrm{R}(-/-)$ \\
\hline \multicolumn{4}{|c|}{ Apomorphine (ME) } \\
\hline Vehicle & $143.0 \pm 19.8$ & $131.2 \pm 15.0$ & $128.0 \pm 15.2$ \\
\hline $5.0 \mathrm{mg} / \mathrm{kg}$ & $81.6 \pm 13.2^{*}$ & $94.4 \pm 10.2^{*}$ & $96.4 \pm 19.4 *$ \\
\hline \multicolumn{4}{|l|}{ SKF82958 } \\
\hline Vehicle & $99.4 \pm 6.0$ & $85.2 \pm 8.8$ & $79.2 \pm 9.4$ \\
\hline $0.30 \mathrm{mg} / \mathrm{kg}$ & $93.6 \pm 11.4$ & $87.6 \pm 6.0$ & $70.0 \pm 7.2$ \\
\hline \multicolumn{4}{|l|}{ Amphetamine } \\
\hline Vehicle & $95.0 \pm 22.2$ & $78.8 \pm 9.6$ & $103.4 \pm 19.4$ \\
\hline $10.0 \mathrm{mg} / \mathrm{kg}$ & $59.6 \pm 9.8$ & $94.6 \pm 14.6$ & $121.4 \pm 22.8$ \\
\hline \multicolumn{4}{|l|}{ Dizocilpine } \\
\hline Vehicle & $81.2 \pm 10.2$ & $102.4 \pm 10.8$ & $130.4 \pm 20.0$ \\
\hline $0.3 \mathrm{mg} / \mathrm{kg}$ & $105.8 \pm 14.2$ & $115.6 \pm 18.0$ & $126.8 \pm 20.4$ \\
\hline
\end{tabular}

Values (arbitrary units) represent mean startle magnitude \pm SEM.

${ }^{*} p<0.05$ compared with vehicle control or main effect of drug treatment (ME).

SKF82958. There were significant main effects of SKF82958 $\left(F_{(1,56)}=25.0 ; p<0.001\right)$ and genotype $\left(F_{(1,56)}=37.4 ; p<0.001\right)$ on PPI in the D1R mice, and, as with apomorphine, there was a significant drug-genotype interaction $\left(F_{(1,56)}=23.7 ; p<0.001\right)$. SKF82958 significantly disrupted PPI in the D1R wild-type $(+/+)$ mice at each prepulse intensity $(p<0.01)$ but had no effect in mice lacking the D1R (Fig. $2 A$ ). Although there were no significant main effects of drug or genotype on startle responding in the D1R mice, there was a significant interaction between drug and genotype $\left(F_{(1,56)}=4.2 ; p<0.05\right)$. This interaction appears to be attributable to a trend toward a decrease in the startle response in D1R wild-type $(+/+)$ mice treated with SKF82958, which was not replicated in the subsequent study, coupled with a nonsignificant increase in startle in D1R knock-out (-/-) mice (Table 1).

When the D2R mice were treated with SKF82958, there was a significant main effect of drug on PPI $\left(F_{(1,49)}=74.2 ; p<0.001\right)$, but there were no detected effects of genotype or interactions between drug treatment and genotype. SKF82958 significantly decreased PPI in the D2R mice regardless of genotype (Fig. 2B). There were no effects of genotype or SKF82958 on startle reactivity (Table 2).

\section{Amphetamine}

D1R mice were treated with the indirect DA agonist amphetamine. There was a significant main effect of drug treatment on PPI in the D1R mice $\left(F_{(1,113)}=48.2 ; p<0.001\right)$, but there were no effects of genotype or interactions detected (Fig. $3 A$ ). As with the D3 and D4 receptor knock-out $(-/-)$ mice studied previously (Ralph et al., 1999), amphetamine significantly disrupted PPI in mice lacking the D1R. Amphetamine also had a significant main effect on startle responding in the D1R mice $\left(F_{(1,113)}=16.6 ; p<\right.$ 0.01 ), but there was neither a main effect of genotype nor a significant interaction between drug treatment and genotype. Amphetamine significantly lowered the acoustic startle response in both the D1R wild-type $(+/+)$ and mutant $(-/-)$ mice (Table 1$)$.

We reported previously that N5 D2R knock-out (-/-) mice do not show deficits in PPI after treatment with amphetamine (Ralph et al., 1999). To confirm these findings in mice that had been backcrossed three additional generations onto the C57BL/6J line, we tested N8 D2R mutant mice with $10.0 \mathrm{mg} / \mathrm{kg}$ amphetamine. Although there were trends toward effects of both genotype $\left(F_{(2,28)}=2.8 ; p=0.08\right)$ and drug treatment $\left(F_{(1,28)}=3.0\right.$; $p=0.09)$ on PPI, there was more importantly a significant genotype by drug treatment interaction $\left(F_{(2,28)}=5.5 ; p<0.01\right)$. Similar to our previous findings, amphetamine significantly reduced PPI in the D2 wild-type $(+/+)$ mice $\left(F_{(1,7)}=10.2 ; p<\right.$ $0.01)$ but had no effect in either the D2 heterozygous $(+/-)$ or knock-out (-/-) mice (Fig. 3B). There were no significant effects of genotype or drug treatment on startle reactivity (Table 2).

\section{Dizocilpine}

In the last set of experiments, we investigated the role of subtypespecific DA receptors in the action of the noncompetitive NMDA receptor antagonist, dizocilpine. When D1R mice were treated with $0.3 \mathrm{mg} / \mathrm{kg}$ dizocilpine, there was a significant main effect of drug treatment on PPI $\left(F_{(1,140)}=64.3 ; p<0.001\right)$, but there were no effects of genotype, nor were there any interactions between drug treatment and genotype. Regardless of genotype, dizocilpine disrupted PPI in all groups of D1R wild-type and mutant mice (Fig. 4A). In addition, treatment with dizocilpine had no significant effect on acoustic startle responding in the D1R mutant mice (Table 1).

When the D2R mice were treated with dizocilpine, there was a significant effect on PPI $\left(F_{(1,33)}=47.9 ; p<0.001\right)$, but there was no main effect of genotype and no interaction between drug and genotype. Treatment with dizocilpine reduced PPI similarly in each of the D2R mice (Fig. 4B). There were no significant effects of drug treatment or genotype on startle reactivity in the D2R mice (Table 2).

\section{DISCUSSION}

Using genetically altered mice in combination with pharmacological manipulations, the present experiments examined the role of both the D1 and D2 subtypes of DA receptors in the modulation of PPI. We report three main findings. First, for the direct DA agonists tested, the disruptive effects on PPI appear to be mediated by the $\mathrm{D} 1 \mathrm{R}$ in mice. The direct D1/D2 receptor agonist apomorphine and the preferential D1-like agonist SKF82958 had no effect on PPI in mice lacking D1Rs, but both drugs disrupted PPI in D1R wild-type $(+/+)$ mice and in all the D2R mice regardless of genotype. Second, the indirect DA agonist amphetamine exerts its disruptive effects via the D2R but not the D1R. Regardless of genotype, the indirect DA agonist amphetamine significantly reduced PPI in all of the D1R mice. However, confirming our previous report (Ralph et al., 1999), amphetamine significantly disrupted PPI only in the D2R wild-type $(+/+)$ mice and was ineffective in both the D2R heterozygous $(+/-)$ and knock-out $(-/-)$ mice. Last, the NMDA antagonist dizocilpine reduced PPI in mice lacking either D1Rs or D2Rs, confirming that the PPI-disruptive effects of dizocilpine are independent of the D1R and the D2Rs in mice.

After treatment with either apomorphine or SKF82958, mice lacking the D1R do not show disruptions in PPI, whereas D2R knock-out $(-/-)$ mice have significantly reduced PPI. Similarly, the PPI-disruptive effects of SKF82958 in mice are blocked by a D1-like antagonist and not by a D2-like antagonist (RalphWilliams et al., 2002). These findings indicate that the D1R, but not the D2R, is essential for these direct agonists to disrupt PPI in mice. Furthermore, in the complete absence of the D2R, a direct D1-like agonist reduced PPI, suggesting a lack of synergistic D1/D2 receptor modulation of PPI in mice. We have reported previously that direct D1-like stimulation alone, by either SKF82958 or dihydrexidine, reduces PPI in inbred mouse strains (Ralph-Williams et al., 2002). Similarly, others have found that 
A.

D1R WT $(+/+)$

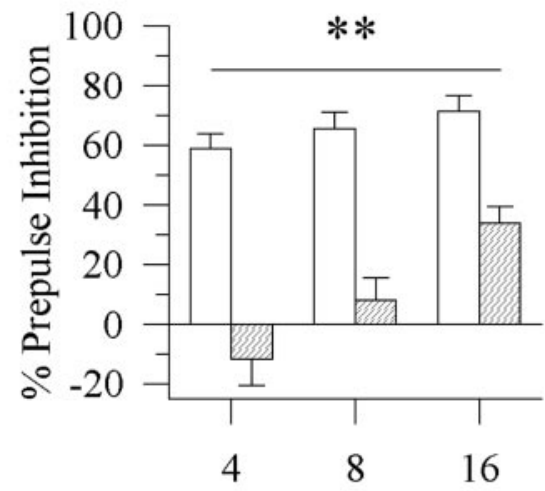

D1R KO (-/-)

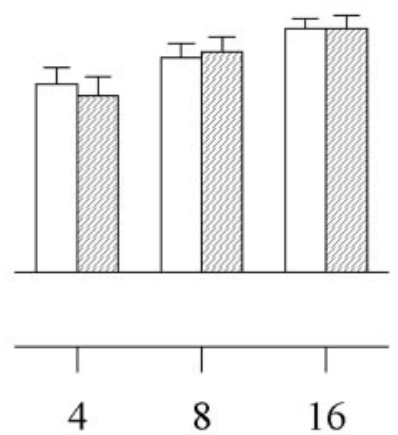

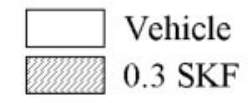

$0.3 \mathrm{SKF}$

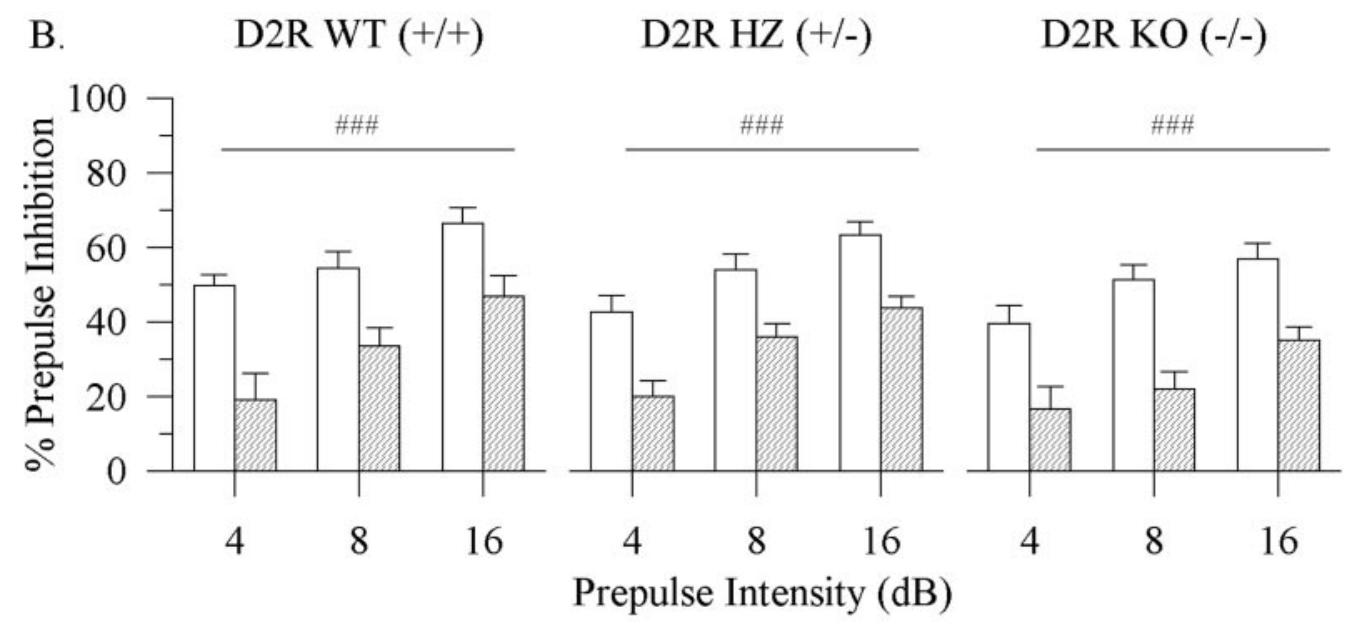

Figure 2. PPI levels in D1R and D2R mutant mice with vehicle control (water; open bars) or SKF82958 (SKF) (0.3 mg/kg; hatched bars). A, The D1-like agonist SKF82958 produced deficits in PPI in the D1R wild-type $(W T)(+/+)$ mice but failed to produce deficits in the D1R knock-out $(K O)(-/-)$ mice. $H Z$, Heterozygous. ${ }^{* *} p<0.01$ compared with vehicle control. $B$, SKF82958 significantly reduced PPI in each of the D2R genotypes (overall drug effect, $\# \#<0.001)$. Error bars indicate mean \% PPI \pm SEM.

the D1-like agonist SKF81297 disrupts PPI in mice, with a suggestion that this effect might be attenuated in mice lacking D5 receptors (Holmes et al., 2001). These reports indicate that D1like receptors may modulate PPI in mice independently of D2R. Although several studies have shown that the mixed D1/D2 agonist apomorphine disrupts PPI in mice (Dulawa and Geyer, 1996; Curzon and Decker, 1998; Ralph et al., 2001b), to date there are no reports of a direct preferential D2-like agonist decreasing PPI in mice except at relatively high, nonselective doses (Ralph-Williams et al., 2002). In contrast, direct D2-like agonists robustly disrupt PPI in rats, whereas direct D1-like agonists appear to work only at high doses or in combination with subthreshold doses of D2-like agonists (Geyer et al., 2001). Taken together with the effects of D1-like and D2-like agonists on PPI in two strains of mice (Ralph-Williams et al., 2002), these data suggest a difference between rats and mice in the modulation of PPI by direct DA agonists. Although it has been postulated that D1Rs and D2Rs interact synergistically to modulate PPI in rats (Peng et al., 1990; Schwarzkopf et al., 1993; Wan et al., 1996; LaHoste et al., 2000), there might be something fundamentally different about the way the D1Rs and D2Rs control PPI in mice. Because our data provide strong evidence that the D1R has a more prominent and independent role in the modulation of PPI in mice than in rats, further studies are warranted to characterize species differences in the physiological and cellular processes related to the dopaminergic systems of rats and mice. It is important to note that there is a growing literature describing strain differences in the amount of PPI, startle reactivity, rates of habituation, and sensitivity to pharmacological manipulations in mice, suggesting that even within a species there are different genetically determined physiological mechanisms regulating these behavioral phenomena (Geyer et al., 2002).

Although the D1Rs appear to be essential for the effects of direct DA agonists on PPI in mice, the D2Rs appear to be more critical to the effects of manipulations that increase synaptic concentrations of DA, such as the indirect DA agonist amphetamine or the lack of the reuptake transporter in the DAT $(-/-)$ mice. In the DAT $(-/-)$ mice, a D2-like antagonist was effective in reversing the deficit in PPI, whereas a D1-like antagonist was ineffective (Ralph et al., 2001a). As with amphetamine, the deficit in PPI in DAT $(-/-)$ mice appears to be attributable to synaptic DA acting on D2-like receptors. Because genetic backgrounds are known to affect behavioral phenotypes, including PPI (Dulawa and Geyer, 1996; Bullock et al., 1997; Logue et al., 1997; Paylor and Crawley, 1997), we challenged N8 D2R mutant mice with amphetamine to confirm our previous findings in an N5 genera- 
A.

D1R WT $(+/+)$

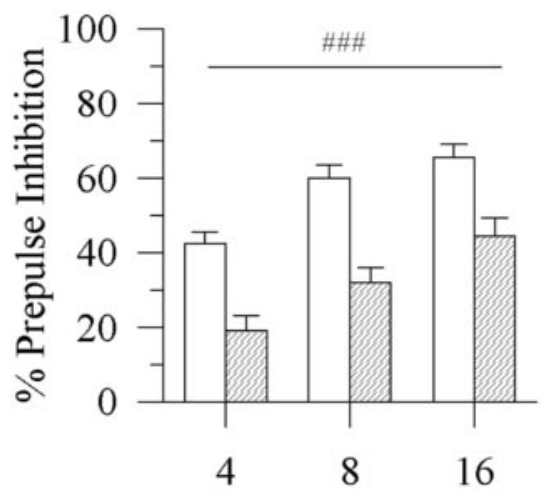

B.

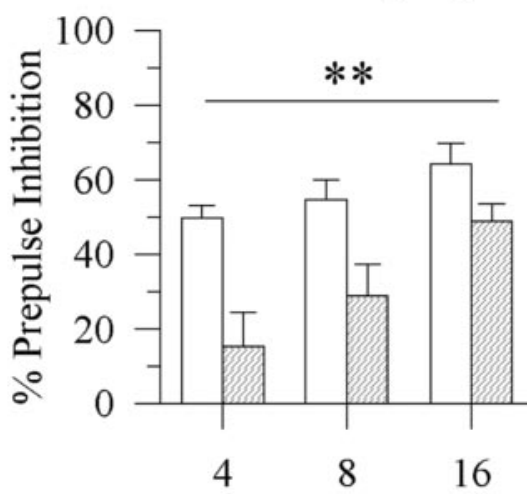

D1R HZ (+/-)

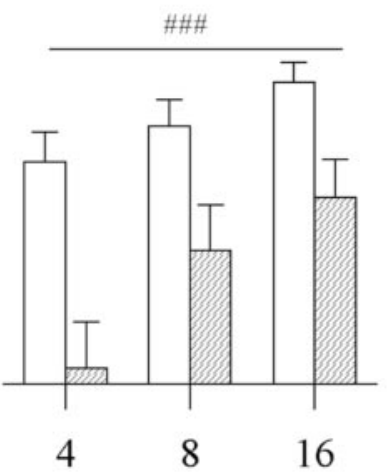

D2R HZ (+/-)

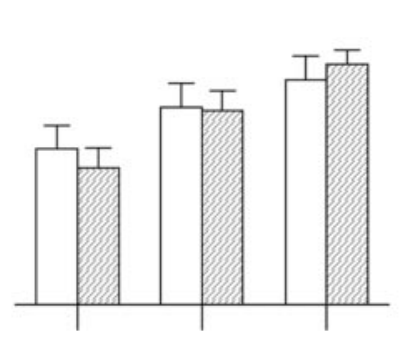

4

8

16

Prepulse Intensity $(\mathrm{dB})$

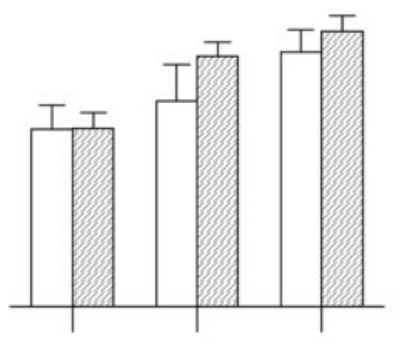

$\begin{array}{lll}4 & 8 & 16\end{array}$

Vehicle $10.0 \mathrm{AMPH}$

Figure 3. PPI levels for D1R and D2R mutant mice with vehicle control (water; open bars) or amphetamine $($ AMPH $)(10 \mathrm{mg} / \mathrm{kg} ;$ hatched bars $)$. A, All D1R mice treated with the indirect DA agonist amphetamine displayed significant reductions in PPI compared with vehicle-treated mice (overall drug effect, $\left.{ }^{\# \# \#} p<0.001\right)$. B, Post hoc ANOVAs revealed that amphetamine significantly reduced PPI at the 4,8 , and $16 \mathrm{~dB}$ prepulse intensities in D2R wild-type $(W T)(+/+)$ mice $(* * p<0.01$ compared with vehicle control) but had no significant effect in the heterozygous $(H Z)(+/-)$ or knock-out $(K O)$ $(-/-)$ mice. Error bars indicate mean $\%$ PPI \pm SEM.

tion of D2R mice (Ralph et al., 1999). As predicted, N8 D2R heterozygous $(+/-)$ and knock-out $(-/-)$ mice failed to show reduced PPI after treatment with amphetamine. Thus, of the D1, D2, D3, and D4 receptor subtypes, only the D2R is essential for amphetamine to disrupt PPI in mice. Furthermore, backcrossing the D2R mutant mice three more generations onto the C57BL/6J line did not change the ability of amphetamine to reduce PPI in the D2R heterozygous $(+/-)$ or knock-out $(-/-)$ mice. In addition, we did not find a gene-dose effect in the N8 D2R mice treated with amphetamine, a finding that is also consistent with our previous report in N5 D2R mutant mice (Ralph et al., 1999). However, there were some differences noted between the two generations of $\mathrm{D} 2 \mathrm{R}$ mice. In contrast to our previous report, amphetamine did not significantly reduce startle reactivity in any of the N8 D2R mice, suggesting that there is some difference in the mechanisms that regulate the startle response in the N5 and $\mathrm{N} 8$ generations of D2R mutant mice. In contrast to the N5 D2R mice, one group of the N8 D2R knock-out $(-/-)$ mice also had lower PPI than wild-type $(+/+)$ controls, an effect that disappeared with subsequent testing. Although there might be a transient difference in the mechanisms that control PPI between the N5 and N8 generations of D2R mutant mice, ultimately these findings still indicate that the $\mathrm{D} 2 \mathrm{R}$ is involved in the modulation of PPI in mice. Accordingly, these data corroborate findings in rats, suggesting that the $\mathrm{D} 2 \mathrm{R}$ is critical to the influences of changes in synaptic DA on PPI.

Overall, no gene-dose effect was detected in this study for either the D1R or D2R mutant mice. The lack of a gene-dose effect in the N8 D2R mice treated with amphetamine is consistent with our previous report in N5 D2R mutant mice (Ralph et al., 1999). However, although the D2R heterozygous (+/-) mice behaved similarly to the D2R knock-outs $(-/-)$ in their PPI response to amphetamine, the D1R heterozygous $(+/-)$ mice were indistinguishable from their wild-type $(+/+)$ controls in their PPI response to apomorphine. These data contrast with the consistently observed intermediate phenotypes for unconditioned locomotor activity (Kelly et al., 1998) and intravenous morphine self-administration (Elmer et al., 2002) in D2R heterozygous $(+/-)$ mice compared with both of the other genotypes. Similarly, D1R heterozygous $(+/-)$ mice were partially impaired on a spatial learning task (Smith et al., 1998). No definitive explanation can be offered for these different patterns of behavior in heterozygous receptor mutant mice, but the simplest suggestion is that lower levels of receptor expression are sufficient for full efficacy to 
A. D1R WT $(+/+)$

D1R HZ (+/-)

D1R KO (-/-)
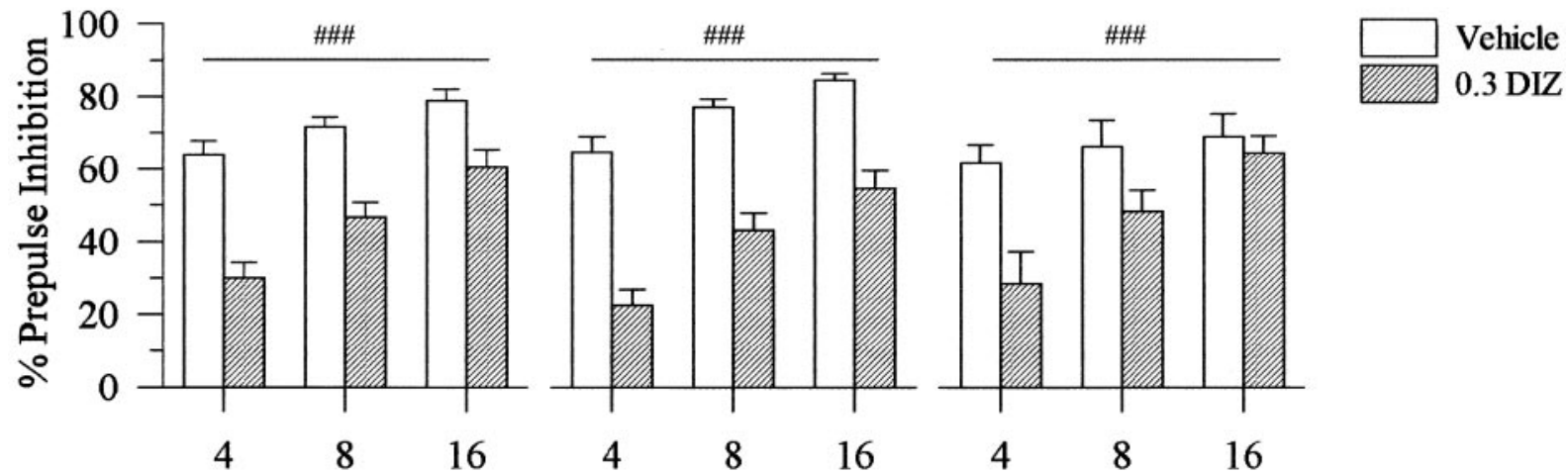

B.

D2R WT (+/+)

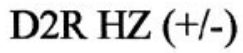

D2R KO (-/-)
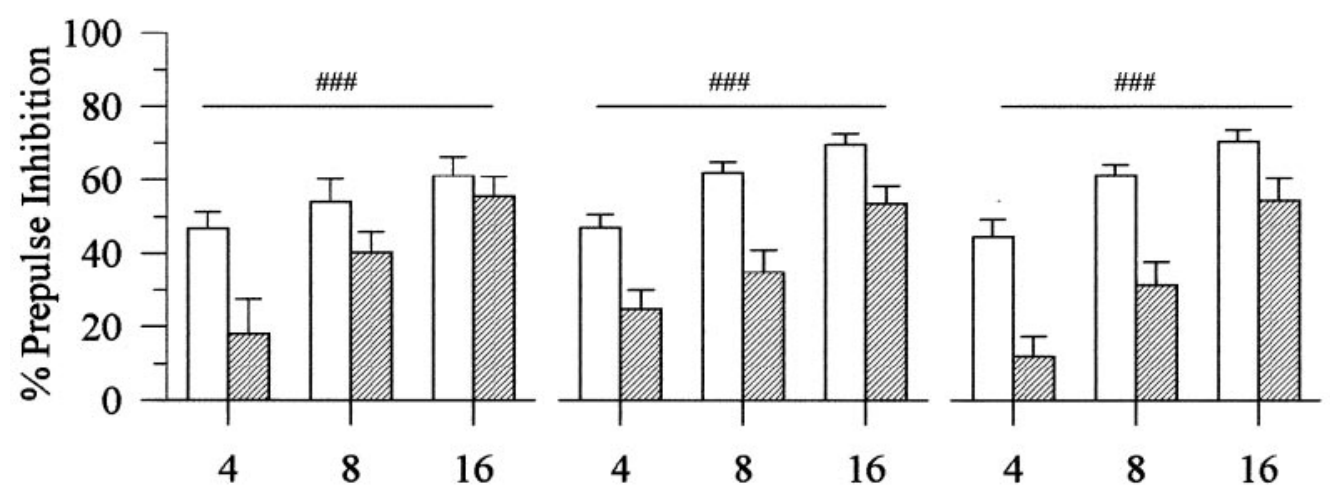

Prepulse Intensity $(\mathrm{dB})$

Figure 4. PPI levels in D1R and D2R mice after pretreatment with vehicle control (water; open bars) or dizocilpine (DIZ) (0.3 mg/kg; hatched bars). Regardless of genotype, the noncompetitive NMDA receptor antagonist dizocilpine significantly disrupted PPI in the D1R $(A)$ and D2R $(B)$ wild-type $(W T)(+/+)$, heterozygous $(H Z)(+/-)$, and knock-out $(K O)(-/-)$ mice (overall drug effect, $\left.{ }^{\# \# ~} p<0.001\right)$. Error bars indicate mean $\%$ PPI \pm SEM.

some, but not all, stimuli. Because only single doses of the various drugs were tested in the D1R and D2R mice, it is possible that additional testing with dose-response studies would reveal more subtle phenotypic distinctions in the heterozygous mice of both strains.

Glutamate and DA interact in several key regions in the brain that are known to regulate PPI in rodents. As such, several pharmacological studies have focused on distinguishing between the effects of glutamate and those of DA on PPI in rodents. Noncompetitive NMDA receptor antagonists, such as phencyclidine and dizocilpine, reliably reduce PPI in rats (for review, see Geyer et al., 2001). However, it is thought that these disruptions of PPI produced by noncompetitive NMDA antagonists are independent of the DA system because neither D1-like nor D2-like antagonists reverse the PPI deficits produced by either phencyclidine or dizocilpine (Keith et al., 1991; Bakshi et al., 1994). Similarly, noncompetitive NMDA receptor antagonists robustly disrupt PPI in mice, and the disruptions are not reversed by haloperidol (Curzon and Decker, 1998; Furuya et al., 1999). Here, treatment with dizocilpine disrupted PPI in mice lacking either D1Rs or D2Rs, further substantiating the fact that the D1Rs and D2Rs are not necessary for an NMDA antagonist to reduce PPI in mice. Thus, these findings support the hypothesis that the effects of dizocilpine on PPI are independent of the DA
D1Rs and D2Rs in mice. The apparent lack of disrupted PPI by dizocilpine in both the D1R $(-/-)$ and D2R $(+/+)$ mice at the 16 $\mathrm{dB}$ prepulse intensity matches a pattern reported in rats in which another NMDA antagonist, phencyclidine, was able to disrupt PPI at only the lower prepulse intensity (Keith et al., 1991). These findings highlight the fact that certain strains of mice and rats may be more sensitive to the PPI-disruptive effects of NMDA antagonists.

The deficits in PPI produced by our various pharmacological and genetic manipulations were not related consistently to changes in acoustic startle reactivity. For instance, apomorphine significantly lowered startle reactivity in both D1R and D2R mutant mice, but the D1R $(-/-)$ mice failed to show disrupted PPI. In addition, dizocilpine significantly disrupted PPI in both the D1R and D2R mice without altering startle reactivity. Amphetamine also had no effect on startle in any group of $\mathrm{D} 2 \mathrm{R}$ mice but significantly reduced PPI in only the D2R wild-type $(+/+)$ mice. Taken together, these results further confirm that independent dopaminergic or glutamatergic mechanisms regulate PPI and acoustic startle response in mice. Furthermore, the lack of significant interactions between drug treatment and genotype on measures of startle reactivity indicates that neither D1Rs nor D2Rs are involved in the reductions in startle reactivity produced by apomorphine. 
The present findings raise the possibility of an important difference between the mechanisms underlying the effects of direct versus indirect agonists, in which direct DA agonists modulate PPI via the D1R in mice but not in rats, and indirect agonist effects appear to be mediated by the D2R in both mice and rats. Although the present studies do not address this question directly, it is plausible that, compared with rats, there may be differences in presynaptic and postsynaptic receptor densities, distributions of receptor subtypes, or receptor-coupled signal transduction pathways influencing the actions of direct DA agonists in mice. If so, such differences must have relatively little influence on the effects of increased levels of synaptic DA associated with indirect agonists or the lack of DA reuptake [as seen in the DAT $(-/-)$ mice]. Further studies addressing these issues may ultimately lead to a better understanding of the differences between direct and indirect agonism and of the mechanisms that regulate PPI in rodents. Such information may also prove useful in understanding deficient sensorimotor gating in humans.

\section{REFERENCES}

Bakshi VP, Swerdlow NR, Geyer MA (1994) Clozapine antagonizes phencyclidine-induced deficits in sensorimotor gating of the startle response. J Pharmacol Exp Ther 271:787-794.

Braff DL, Geyer MA (1990) Sensorimotor gating and schizophrenia: human and animal model studies. Arch Gen Psychiatry 47:181-188.

Braff DL, Grillon C, Geyer MA (1992) Gating and habituation of the startle reflex in schizophrenic patients. Arch Gen Psychiatry 49:206-215.

Bullock AE, Slobe BS, Vazquez V, Collins AC (1997) Inbred mouse strains differ in the regulation of startle and prepulse inhibition of the startle response. Behav Neurosci 111:1353-1360.

Curzon P, Decker MW (1998) Effects of phencyclidine (PCP) and $(+)$ M K-801 on sensorimotor gating in CD-1 mice. Prog Neuropsychopharmacol Biol Psychiatry 22:129-146.

Diaz-Torga G, Feierstein C, Libertun C, Gelman D, Kelly MA, Low MJ, Rubinstein M, Becu-Villalobos D (2002) Disruption of the D2 dopamine receptor alters GH and IGF-I secretion and causes dwarfism in male mice. Endocrinology 143:1270-1279.

Drago J, Gerfen CR, Lachowicz JE, Steiner H, Hollon TR, Love PE, Ooi GT, Grinberg A, Lee EJ, Huang SP, Bartlett PF, Jose PA, Sibley DR, Westphal H (1994) Altered striatal function in a mutant mouse lacking D1A dopamine receptors. Proc Natl Acad Sci USA 91:1256412568 .

Dulawa SC, Geyer MA (1996) Psychopharmacology of prepulse inhibition in mice. Chin J Physiol 39:139-146.

Dulawa SC, Hen R, Scearce-Levie K, Geyer MA (1997) Serotonin1B receptor modulation of startle reactivity, habituation, and prepulse inhibition in wild-type and serotonin1B knock-out mice. Psychopharmacology (Berl) 132:125-134.

Elmer GI, Pieper JO, Rubinstein M, Low MJ, Grandy DK, Wise RA (2002) Failure of intravenous morphine to serve as an effective instrumental reinforcer in dopamine D2 receptor knock-out mice. J Neurosci 22:RC224(1-6)

Furuya Y, Kagaya T, Ogura H, Nishizawa Y (1999) Competitive NMDA receptor antagonists disrupt prepulse inhibition without reduction of startle amplitude in a dopamine receptor-independent manner in mice. Eur J Pharmacol 364:133-140.

Geyer MA, Swerdlow NR (1998) Measurement of the startle response and its use in preclinical measures of prepulse inhibition and habituation. In: Current protocols in neuroscience (Crawley JN, Skolnick P, eds), pp 8.7.1-8.7.15. New York: Wiley.
Geyer MA, Krebs-Thomson K, Braff DL, Swerdlow NR (2001) Pharmacological studies of prepulse inhibition models of sensorimotor gating deficits in schizophrenia: a decade in review. Psychopharmacology (Berl) 156:117-154.

Geyer MA, McIlwain KL, Paylor R (2002) Mouse genetic models for prepulse inhibition: an early review. Mol Psychiatry, in press.

Hoffman HS, Ison JR (1980) Reflex modification in the domain of startle: I. Some empirical findings and their implications for how the nervous system processes sensory input. Psychol Rev 87:175-189.

Holmes A, Hollon TR, Gleason TC, Liu Z, Dreiling J, Sibley DR, Crawley JN (2001) Behavioral characterization of dopamine D5 receptor null mutant mice. Behav Neurosci 115:1129-1144.

Keith VA, Mansbach RS, Geyer MA (1991) Failure of haloperidol to block the effects of phencyclidine and dizocilpine on prepulse inhibition of startle. Biol Psychiatry 30:557-566.

Kelly MA, Rubinstein M, Asa SL, Zhang G, Saez C, Bunzow JR, Allen RG, Hnasko R, Ben-Jonathan N, Grandy DK, Low MJ (1997) Pituitary lactotroph hyperplasia and chronic hyperprolactinemia in dopamine D2 receptor-deficient mice. Neuron 19:103-113.

Kelly MA, Rubinstein M, Phillips TJ, Lessov CN, Burkhart-Kasch S, Zhang G, Bunzow JR, Fang Y, Gerhardt GA, Grandy DK, Low MJ (1998) Locomotor activity in D2 dopamine receptor-deficient mice is determined by gene dosage, genetic background, and developmental adaptations. J Neurosci 18:3470-3479.

LaHoste GJ, Henry BL, Marshall JF (2000) Dopamine D1 receptors synergize with D2, but not D3 or D4, receptors in the striatum without the involvement of action potentials. J Neurosci 20:6666-6671.

Logue SF, Owen EH, Rasmussen DL, Wehner JM (1997) Assessment of locomotor activity, acoustic and tactile startle, and prepulse inhibition of startle in inbred mouse strains and F1 hybrids: implications of genetic background for single gene and quantitative trait loci analyses. Neuroscience 80:1075-1086.

McGhie A, Chapman J (1961) Disorders of attention and perception in early schizophrenia. Br J Med Psychol 34:103-116.

Paylor R, Crawley JN (1997) Inbred strain differences in prepulse inhibition of the mouse startle response. Psychopharmacology (Berl) 132:169-180.

Peng RY, Mansbach RS, Braff DL, Geyer MA (1990) A D2 dopamine receptor agonist disrupts sensorimotor gating in rats: implications for dopaminergic abnormalities in schizophrenia. Neuropsychopharmacology 3:211-218.

Ralph RJ, Varty GB, Kelly MA, Wang YM, Caron MG, Rubinstein M, Grandy DK, Low MJ, Geyer MA (1999) The dopamine D2, but not D3 or D4, receptor subtype is essential for the disruption of prepulse inhibition produced by amphetamine in mice. J Neurosci 19:4627-4633.

Ralph RJ, Paulus MP, Fumagalli F, Caron MG, Geyer MA (2001a) Prepulse inhibition deficits and perseverative motor patterns in dopamine transporter knock-out mice: differential effects of D1 and D2 receptor antagonists. J Neurosci 21:305-313.

Ralph RJ, Paulus MP, Geyer MA (2001b) Strain-specific effects of amphetamine on prepulse inhibition and patterns of locomotor behavior in mice. J Pharmacol Exp Ther 298:148-155.

Ralph-Williams RJ, Lehmann-Masten V, Geyer MA (2002) Dopamine D1 rather than D2 receptor agonists disrupt prepulse inhibition of startle in mice. Neuropsychopharmacology:http://www.acnp.org/citations/Npp062002331, in press.

Schwarzkopf SB, Bruno JP, Mitra T (1993) Effects of haloperidol and SCH 23390 on acoustic startle and prepulse inhibition under basal and stimulated conditions. Prog Neuropsychopharmacol Biol Psychiatry 17:1023-1036.

Smith DR, Striplin CD, Geller AM, Mailman RB, Drago J, Lawler CP, Gallagher M (1998) Behavioural assessment of mice lacking D1A dopamine receptors. Neuroscience 86:135-146.

Swerdlow NR, Braff DL, Taaid N, Geyer MA (1994) Assessing the validity of an animal model of deficient sensorimotor gating in schizophrenic patients. Arch Gen Psychiatry 51:139-154.

Wan FJ, Taaid N, Swerdlow NR (1996) Do D1/D2 interactions regulate prepulse inhibition in rats? Neuropsychopharmacology 14:265-274. 